\title{
The Utilization of Fructose by Escherichia coli
}

\section{PROPERTIES OF A MUTANT DEFECTIVE IN FRUCTOSE 1-PHOSPHATE KINASE ACTIVITY}

\author{
By T. FERENCI* and H. L. KORNBERG \\ Department of Biochemistry, School of Biological Sciences, University of Leicester, Leicester LE1 7RH, U.K.
}

(Received 23 October 1972)

\begin{abstract}
1. The isolation and properties of a mutant of Escherichia coli devoid of fructose 1phosphate kinase activity are described. 2 . This mutant grew in media containing any one of a variety of substances, including hexoses, hexose 6-phosphates, sugar acids and glucogenic substrates, at rates not significantly different from those at which the parent organism grew on these substrates. However, only the parent grew on fructose or fructose 1-phosphate. 3. Fructose and fructose 1-phosphate inhibit the growth of the mutant, but not of its parent, on other carbon sources. 4. Even though not previously exposed to fructose, the mutant took up $\left[{ }^{14} \mathrm{C}\right]$ fructose rapidly but to only a small extent: $\left[{ }^{14} \mathrm{C}\right]$ fructose 1-phosphate was identified as the predominant labelled product. In contrast, the equally rapid but more extensive uptake of $\left[{ }^{14} \mathrm{C}\right]$ fructose by the parent organism required prior growth in the presence of fructose.
\end{abstract}

Although Escherichia coli contains a fructokinase that catalyses the formation of fructose 6-phosphate and ADP from fructose and ATP (Sebastian \& Asensio, 1967), the uptake and rapid utilization of fructose for growth is generally accepted to necessitate the activity of a phosphoenolpyruvate-dependent phosphotransferase system (Kundig et al., 1964). In this system, Enzyme I catalyses the transfer of the phosphate group from phosphoenolpyruvate to a nitrogen atom of a histidine residue in a small protein (HPr) according to reaction (1) (Kundig \& Roseman,
The role of the fructose-phosphoenolpyruvate phosphotransferase in the uptake of, and growth on, fructose by $E$. coli has been demonstrated clearly through the isolation of mutants devoid of Enzyme I or HPr (for review, see Lin, 1970) or of the fructosespecific Enzyme II (Ferenci \& Kornberg, 1971a). No such clear evidence exists on the fate of fructose 1-phosphate. The enzyme that catalyses the ATPdependent phosphorylation of fructose 1-phosphate to fructose 1,6-diphosphate, fructose 1-phosphate kinase (reaction 4):

$$
\text { Fructose 1-phosphate }+ \text { ATP } \rightarrow \text { fructose 1,6-diphosphate + ADP }
$$

1971); in a subsequent step (reaction 2) a multicomponent Enzyme II catalyses the transfer of phosphate from the phosphorylated protein (phospho-HPr) to fructose, to form the phosphorylated sugar. It is further known that in $E$. coli (Fraenkel, 1968 ; Ferenci \& Kornberg, 1971a), as in Aerobacter aerogenes (Hanson \& Anderson, 1968) and Bacillus subtilis (Marquet et al., 1970), the phosphorylated product of reaction (2) is virtually only fructose 1phosphate when a low concentration $(\leqslant 2 \mathrm{mM})$ of fructose is present, though fructose 6-phosphate can also be formed at high fructose concentrations (Ferenci \& Kornberg, 1971b): was first discovered in Bacteroides symbiosus (Reeves et al., 1966). It has also been demonstrated to be inducibly formed by $E$. coli after exposure of that organism to fructose (Fraenkel, 1968b) or fructose 1-phosphate (Ferenci \& Kornberg, 1971a), but no mutants of $E$. coli devoid of this enzyme have yet been described. It is the purpose of the present paper to remedy this deficiency.

\section{Materials and Methods}

Isolation of the mutant

The parent organism used for the preparation of the mutant was a derivative of the Cavalli strain of

$$
\begin{array}{r}
\text { Phosphoenolpyruvate }+ \text { HPr } \stackrel{\text { Enzyme I }}{\longrightarrow} \text { phospho-HPr }+ \text { pyruvate } \\
\text { Phospho-HPr }+ \text { fructose } \stackrel{\text { Enzyme II }}{\longrightarrow} \text { fructose phosphate }+ \text { HPr }
\end{array}
$$

Sum: Phosphoenolpyruvate + fructose $\rightarrow$ fructose phosphate + pyruvate

* Present address: Department of Microbiology, University of Sheffield, Sheffield S10 2TN, U.K.

Vol. 132 
E. coli K12, designated AT 2243-11' (Hfr.C,met,ura, $\left.u h p^{c}\right)$; it had been previously mutated to form constitutively the uptake system for hexose phosphates (Ferenci et al., 1971). (Abbreviations used indicate a requirement for $m e t=$ methionine, or $u r a=$ uracil; the marker $u h p^{c}$ specifies the constitutive formation of an uptake system for hexose phosphates.) In contrast to wild-type strains of $E$. coli, mutants carrying this marker $\left(u h p^{c}\right)$ grow readily on fructose 1-phosphate as sole carbon source. The mutant AT 2243-11 $\mathrm{c}-25$, devoid of fructose 1-phosphate kinase activity, was derived from AT $2243-11^{c}$ by treatment of suspensions of this organism with $N$ methyl- $N^{\prime}$-nitro- $N$-nitrosoguanidine, as described by Adelberg et al. (1965), and selection with penicillin (Gorini \& Kaufman, 1959) of mutants unable to grow on fructose 1-phosphate. Survivors of the penicillin treatment were spread on plates containing $1 \%$ (w/v) Oxoid Ionagar, salts (Ashworth \& Kornberg, 1966) and 10mm-glucose; the colonies that grew on these plates were replica-plated on to plates containing $2 \mathrm{~mm}$-fructose as carbon source. Colonies that grew on the former but not the latter medium were purified by repeated isolation of single colonies: one such colony, stored on an Oxoid nutrient-agar slope, was the source of the cultures used in the present work.

Cultures of this mutant, and its parent, have been deposited with the $E$. coli Genetic Stock Center, Department of Microbiology, Yale University, New Haven, Conn. 06520, U.S.A.

\section{Growth of the organisms}

Since both parent and mutant organisms require methionine and uracil for growth, these substances were added to all growth media to final concentrations of $40 \mu \mathrm{g} / \mathrm{ml}$. The procedures used for the aerobic growth at $37^{\circ} \mathrm{C}$ of the organisms and for measurements of cell density were otherwise those described by Ashworth \& Kornberg (1966).

\section{Measurement of enzymic activities}

The fructose 1-phosphate kinase activity of ultrasonic extracts of $E$. coli was measured as described by Ferenci \& Kornberg (1971a). The fructosephosphoenolpyruvate phosphotransferase activity of toluene-treated cell suspension was determined essentially by the method of Kornberg \& Reeves (1972), except that 1.0mm-EDTA (disodium salt) was included in the buffer used for toluene treatment of the cells, and that the phosphoenolpyruvate concentration used in the assay was raised to $2.5 \mathrm{~mm}$. The phosphotransferase reaction was started by the addition of $1 \mu \mathrm{mol}$ of fructose to each experimental cuvette ( $1 \mathrm{ml}$ reaction vol.).

\section{Measurement of the uptake of $\left[U-{ }^{14} C\right]$ fructose}

The uptake of labelled fructose $(0.1 \mathrm{mM}, 0.29 \mu \mathrm{Ci} /$ $\mathrm{ml})$ by washed suspensions of cells $(0.3 \mathrm{mg}$ dry wt. $/ \mathrm{ml})$ was measured as previously described (Morgan \& Kornberg, 1969).

\section{Chromatography of accumulated intracellular material}

A washed suspension of glycerol-grown mutant AT $2243-11^{\mathrm{c}}-25$ containing $5.4 \mathrm{mg}$ dry wt. of cells in $12 \mathrm{ml}$ of medium was incubated with $0.1 \mathrm{~mm}-\left[\mathrm{U}-{ }^{14} \mathrm{C}\right]-$ fructose under the conditions normally used for measurement of the uptake of that labelled sugar, except that the incubation was performed at $20^{\circ} \mathrm{C}$ and was continued for $10 \mathrm{~min}$. The cells were harvested by centrifugation for $5 \mathrm{~min}$ at $20000 \mathrm{~g}$ and were suspended in $1.0 \mathrm{ml}$ of $7 \%(\mathrm{v} / \mathrm{v}) \mathrm{HClO}_{4}$. The undissolved material was removed by centrifugation; it contained less than $3 \%$ of the total radioactive material taken up by the cells and was discarded. The supernatant was neutralized with $0.3 \mathrm{ml}$ of $4 \mathrm{M}-\mathrm{KOH}$, the precipitate was removed by centrifugation and the supernatant solution was used for chromatography on thin-layer plates, prepared from cellulose powder (MN 300: Macherey, Nagel and Co., D-516 Düren, Germany) applied in a layer $250 \mu \mathrm{m}$ in thickness.

A volume of supernatant solution [ $[10 \mu$, giving approx. 5000 c.p.m. when assayed, in $5 \mathrm{ml}$ of Bray's (1960) fluid, with a Packard series 4000 liquidscintillation counter] was applied as spots to the starting line of each plate for chromatography; approx. $0.1 \mu \mathrm{mol}$ of each authentic sugar phosphate was also thus applied for comparison purposes. After development of the chromatograms in either $1 \mathrm{M}$ ammonium acetate ( $\mathrm{pH} 5)-95 \%(\mathrm{v} / \mathrm{v})$ ethanol-0.1 MEDTA (disodium salt) (30:70:1, by vol.; Wawszkiewicz, 1961) or 2-methylpropan-2-ol-0.1 M$\mathrm{HCl}\left(4: 1, v / v ;\right.$ Steinitz, 1961), free $\left[{ }^{14} \mathrm{C}\right]$ fructose and the unknown labelled product were located by placing the plates into contact with Kodak 'Blue Brand' $\mathrm{X}$-ray film for 3 days. The resultant radioautographs, developed and fixed, were scanned with a JoyceLoebl microdensitometer; the positions of the sugar phosphate standards on the chromatograms were revealed with the molybdate spray of Hanes \& Isherwood (1949).

\section{Materials}

[U- $\left.{ }^{14} \mathrm{C}\right]$ Fructose was purchased from The Radiochemical Centre, Amersham, Bucks., U.K.; sodium phosphoenolpyruvate and disodium fructose 1phosphate were from Sigma (London) Chemical Co. Ltd., Kingston upon Thames, Surrey, U.K.; $N$ methyl- $N$ '-nitro- $N$-nitrosoguanidine was from KochLight Laboratories Ltd., Colnbrook, Bucks., U.K.; and benzylpenicillin (Glaxo Research Ltd.) was 
bought from a local pharmacist. Cellulose powder for t.l.c. plates was from Camlab, Cambridge, U.K.

\section{Results}

The mutant strain AT 2243-11 ${ }^{\mathrm{c}}-25$ was selected by its inability to grow on agar plates containing media with either fructose or fructose 1-phosphate as carbon source, while retaining the ability to grow on glucose. This growth pattern was confirmed by measurement of the increase in cell mass when cultures of the mutant, and of its parent organism AT $2243-11^{\mathrm{c}}$, were shaken aerobically at $37^{\circ} \mathrm{C}$ in liquid media. No differences between the two strains were observed in their rates of doubling on glucose, glucose 6-phosphate, fructose 6-phosphate or glycerol as sole sources of carbon. However, only the parent organism grew readily on fructose or fructose 1phosphate (with doubling times of 69 and $72 \mathrm{~min}$ respectively): the mutant required more than $11 \mathrm{~h}$ to double on $25 \mathrm{~mm}$-fructose and did not grow significantly in $24 \mathrm{~h}$ on $10 \mathrm{~mm}$-fructose 1-phosphate.

A second difference in the behaviour of the mutant and its parent strain is illustrated in Fig. 1. The addition of either fructose or fructose 1-phosphate (but not fructose 6-phosphate) to cultures of the mutant growing on a variety of substances, such as glycerol, glucose, lactose or succinate, markedly slowed their rates of growth, which virtually ceased after about one doubling; this did not occur with the parent organism. This impairment of growth in the presence of fructose or fructose 1-phosphate was likely to be a consequence of the accumulation of toxic amounts of fructose 1-phosphate in the mutant cells. Evidence in support of this view was derived from a number of observations.

Direct measurement of the fructose 1-phosphate kinase activities of extracts of the parent and mutant strains showed that, whereas the enzyme was easily demonstrable in the former organism however grown, and was abundant in extracts of cells grown in the presence of fructose, no significant activity was found in extracts of the mutant even after growth (for less than one generation, Fig. 1) in the presence of fructose (Table 1).

Comparison of the rates at which washed suspensions of the mutant and of its parent took up $0.1 \mathrm{mM}-\left[{ }^{14} \mathrm{C}\right]$ fructose confirmed that both strains were capable of taking up this hexose but differed greatly in the extent to which ${ }^{14} \mathrm{C}$-labelled materials appeared in the cells. Whereas the radioactivity of the parent organism increased rapidly over the $2.5 \mathrm{~min}$ of the experiment illustrated in Fig. 2 and, in this time, corresponded to an incorporation, into a variety of cellular materials, of over $50 \mathrm{nmol}$ of the labelled fructose/mg dry wt. of cells, the suspension of the mutant took up rapidly only about $5 \mathrm{nmol}$ of labelled fructose/mg dry wt. of cells, did not incorporate this

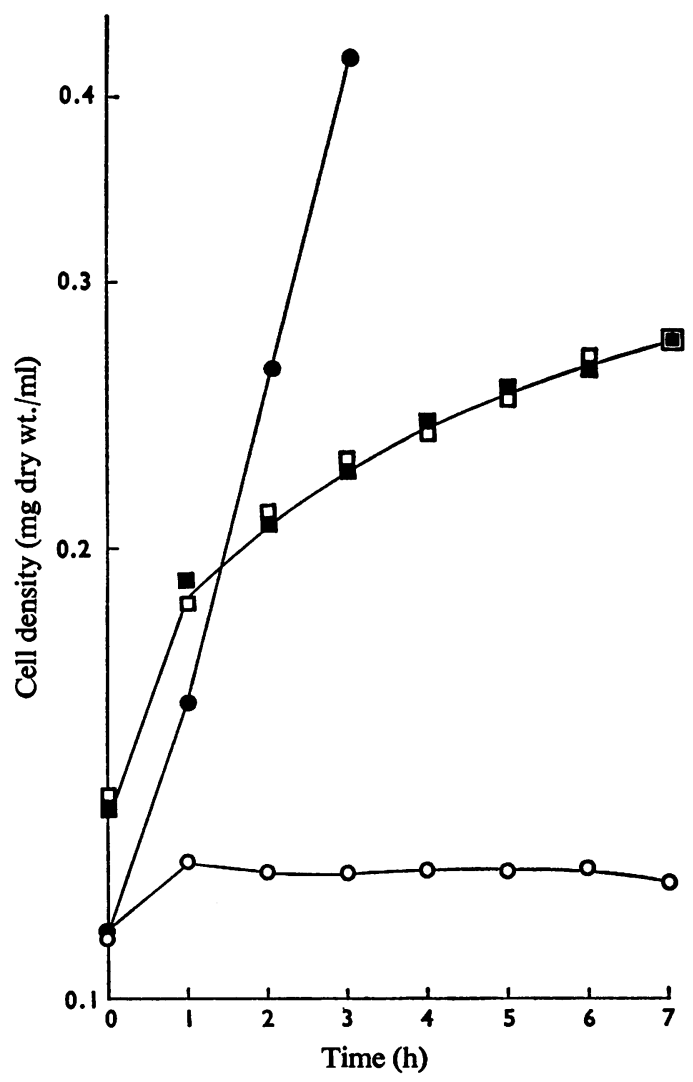

Fig. 1. Effect of fructose and fructose 1-phosphate on the growth of mutant AT 2243-11 $\mathrm{c}-25$ on glycerol

A culture of the mutant, grown in medium containing $25 \mathrm{mM}$-glycerol, was divided into three flasks containing this medium supplemented with $(\bullet)$ nothing, () $10 \mathrm{~mm}$-fructose, or ( $\square$ ) $10 \mathrm{~mm}$-fructose 1-phosphate. A control flask contained harvested cells resuspended in medium containing $10 \mathrm{~mm}$-fructose 1-phosphate as sole carbon source (o). Growth was measured aerobically at $37^{\circ} \mathrm{C}$.

hexose into cellular materials under these conditions, and did so almost totally within the first minute; the radioactivity did not increase thereafter.

Tests of the fate of the labelled fructose taken up by the mutant confirmed the nature of the enzymic lesion in this organism. As shown in Fig. 3, the radioactive material accumulated (which accounted for over $97 \%$ of the $\left[{ }^{14} \mathrm{C}\right]$ fructose taken up: see the Materials and Methods section) was not free fructose but a phosphorylated derivative; the position of that derivative on chromatography in both solvents used for chromatography corresponded to that of authentic

Vol. 132 
Table 1. Fructose 1-phosphate kinase and fructose-phosphoenolpyruvate phosphotransferase activities in E. coli strains used in this work

Fructose 1-phosphate kinase activity was determined in ultrasonic extracts of cells, and fructose-phosphoenolpyruvate phosphotransferase activity in toluene-treated cell suspensions, as described in the Materials and Methods section.

\begin{tabular}{|c|c|c|c|}
\hline \multirow[b]{2}{*}{ Organism } & \multirow[b]{2}{*}{$\begin{array}{l}\text { Carbon source } \\
\text { for growth }\end{array}$} & \multicolumn{2}{|c|}{ Specific activity } \\
\hline & & $\begin{array}{c}\text { Fructose 1-phosphate } \\
\text { kinase } \\
\text { (nmol/min per mg dry wt. of protein) }\end{array}$ & $\begin{array}{l}\text { Fructose-phosphoenolpyruvate } \\
\text { phosphotransferase } \\
\text { (nmol/min"per mg dry wt. of cells) }\end{array}$ \\
\hline $\begin{array}{c}\text { AT } 2243-11^{c} \\
\text { (parent) }\end{array}$ & $\begin{array}{l}\text { Fructose } \\
\text { Glycerol } \\
\text { Fructose plus } \\
\quad \text { glycerol }\end{array}$ & $\begin{array}{r}176 \\
10 \\
105\end{array}$ & $\begin{array}{r}85 \\
9 \\
86\end{array}$ \\
\hline $\begin{array}{l}\text { AT } 2243-11^{\mathrm{c}}-25 \\
\text { (mutant) }\end{array}$ & $\begin{array}{l}\text { Glycerol } \\
\text { Fructose plus } \\
\text { glycerol }\end{array}$ & $\begin{array}{l}\leqslant 1 \\
\leqslant 1\end{array}$ & $\begin{array}{l}115 \\
102\end{array}$ \\
\hline
\end{tabular}

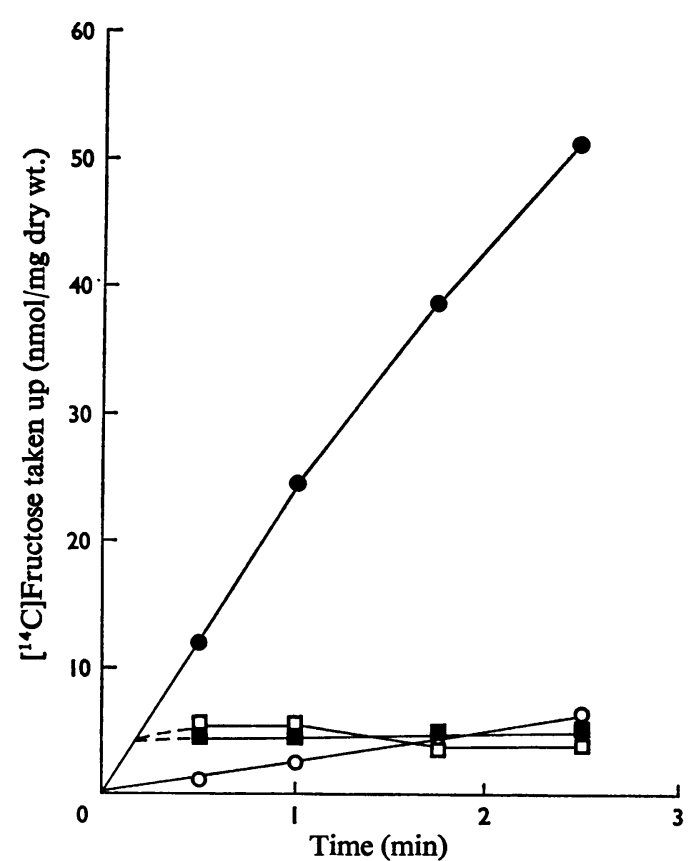

Fig. 2. Uptake of $\left[{ }^{14} \mathrm{Cl}\right.$ fructose at $37^{\circ} \mathrm{C}$ by washed suspensions of the mutant $A T 2243-11^{\mathrm{c}}-25$ and of its parent organism $A T 2243-11^{c}$

The uptake of $0.1 \mathrm{~mm}-\left[\mathrm{U}-{ }^{14} \mathrm{C}\right]$ fructose, at $37^{\circ} \mathrm{C}$, by suspensions of the mutant grown in $25 \mathrm{~mm}$-glycerol in the absence ( $\square$ ) and in the presence ( $\square$ ) of $10 \mathrm{~mm}-$ fructose for about one doubling, and of the parent organism similarly treated $(0, \bullet)$, was measured as described in the Materials and Methods section.

fructose 1-phosphate. No other soluble ${ }^{14} \mathrm{C}$-labelled products were detected in these experiments.

A further difference between strain AT 2243-11 ${ }^{\text {c }}$ and its mutant is that the uptake of $\left[{ }^{14} \mathrm{C}\right]$ fructose by the latter, albeit limited in extent, is catalysed as rapidly by cells grown in the absence of fructose as by cells grown in its presence. This is shown by an experiment (Fig. 4) in which the rates of uptake of $\left[{ }^{14} \mathrm{C}\right]$ fructose by suspensions of both the mutant and its parent were measured at $20^{\circ} \mathrm{C}$ in order to slow down this process. The suspension of mutant cells, which had been grown on glycerol, took up the labelled hexose initially as rapidly as did suspensions of the parent grown on fructose: suspensions of this latter organism grown on glycerol did not take up $\left[{ }^{14} \mathrm{C}\right]$ fructose to any considerable extent. The implication of these findings, that the mutant devoid of fructose 1-phosphate kinase forms in high activity the phosphoenolpyruvate phosphotransferase system that catalyses the uptake and phosphorylation of fructose (reaction 3) under conditions where it is not formed to that extent by its parent, is confirmed by direct assays of the fructose-phosphoenolpyruvate phosphotransferase activity of toluene-treated suspensions of these organisms (Table 1).

\section{Discussion}

The isolation and properties of bacterial mutants devoid of fructose 1-phosphate kinase activity have been reported previously. Kelker et al. (1970) described one such mutant, of $A$. aerogenes; the growth properties (Gay \& Rapoport, 1970) and genetic mapping (Gay et al., 1970) of a similar mutant of $B$. subtilis have also been reported. Both these mutants exhibit many similarities with the $E$. coli mutant described here. In all cases, the addition of fructose to cultures growing on other carbon sources inhibits growth, and fructose 1-phosphate accumulates. Like the $E$. coli mutant, that of $A$. aerogenes formed the fructose-phosphoenolpyruvate phosphotransferase system in high activity even in the absence of fructose 


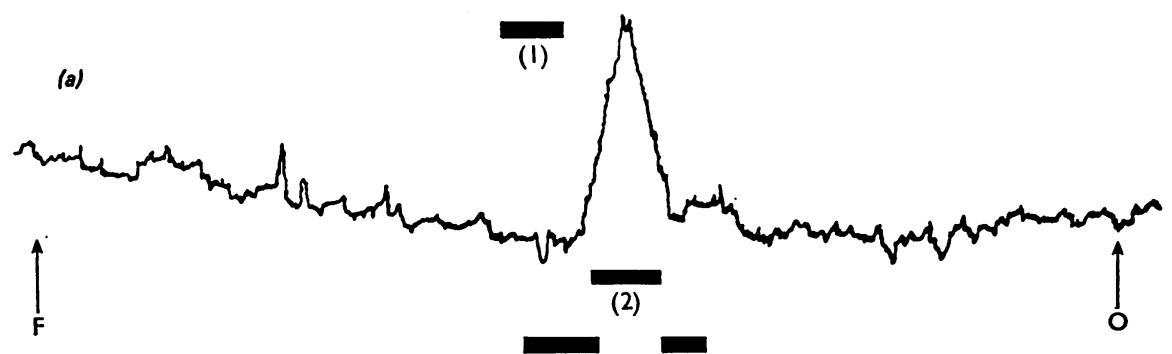

(3) (4)

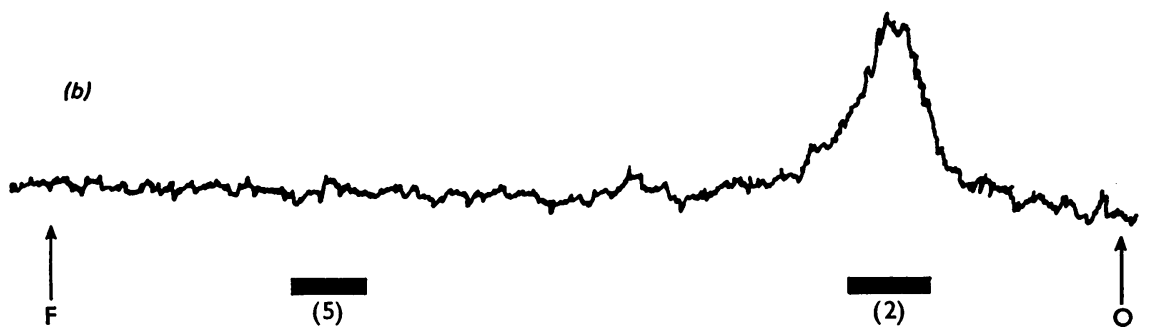

Fig. 3. Densitometer tracings of radioautograms of ${ }^{14} \mathrm{C}$-labelled products formed after exposure of a washed suspension of the mutant $A T 2243-11^{\mathrm{c}}-25$ to $0.1 \mathrm{mM}-\left[U-{ }^{14} \mathrm{C}\right]$ fructose

For experimental details, see the Materials and Methods section. Chromatograms were run in (a) 2-methylpropan-2-ol-0.1 $\mathrm{M}-\mathrm{HCl}(4: 1, \mathrm{v} / \mathrm{v})$ and (b) $1 \mathrm{M}$-ammonium acetate-95\% ethanol-0.1 $\mathrm{M}$-EDTA (disodium salt) (30:70:1, by vol.). The black bars indicate the positions occupied by authentic compounds: (1) fructose 1,6-diphosphate; (2) fructose 1-phosphate; (3) fructose 6-phosphate; (4) glucose 6-phosphate; (5) fructose. The position of origins $(\mathrm{O})$ and the solvent fronts $(\mathrm{F})$ are indicated by arrows.

from growth media, and that of $B$. subtilis catalysed the rapid (though limited) uptake of labelled fructose under all conditions tested. The particular utility of the $E$. coli mutant discussed in the present paper is that it is derived from an organism able to utilize external fructose 1-phosphate under all growth conditions; the necessary role, and fate, of that substance in the catabolism of fructose can thus be directly tested.

Two properties of mutants devoid of fructose 1-phosphate kinase deserve further comment. One is the marked inhibition of growth consequent on the addition of fructose (and, in the case of our $E$. coli mutant, also of fructose 1-phosphate) to cultures growing on other carbon sources. This does not occur if fructose 6-phosphate is added instead, and must be associated with the accumulation of fructose 1phosphate by the mutant cells. Similar instances, in which the accumulation of phosphorylated compounds exerts a toxic (though not lethal) effect have often been reported (Kurahashi \& Wahba, 1958; Englesberg \& Baron, 1959; Nikaido, 1961; Englesberg et al., 1962; Cozzarelli et al., 1965; Böck \& Neidhardt, 1966; Fraenkel, 1968a; Kelker et al.,
1970; Gay \& Rapoport, 1970; Solomon \& Lin, 1972). The basis of this toxicity is not clear. The growth stasis (seen when glucose is added to cultures of mutants devoid of the ability to catabolize glucose 6phosphate, when growing on glucogenic but not when growing on glycolytic substrates) was interpreted by Fraenkel (1968a) as a consequence of the inhibition of fructose 1,6-diphosphatase. This cannot wholly explain the toxic effects exerted by the wide variety of phosphorylated compounds that have been reported as inhibiting growth. It is perhaps more likely that the accumulated materials inhibit the further uptake of growth substrates (for discussion, see Kornberg, 1972, 1973).

A second feature of mutants devoid of fructose 1-phosphate kinase is that they form the fructosephosphoenolpyruvate phosphotransferase system, and consequently rapidly take up $\left[{ }^{14} \mathrm{C}\right]$ fructose, even though they have not previously been exposed to fructose. This might suggest that the mutants of $A$. aerogenes, $B$. subtilis and $E$. coli isolated all involved mutations in portions of the genome that also encompassed a regulator gene. An alternative explanation is that either fructose or fructose 1-phosphate 


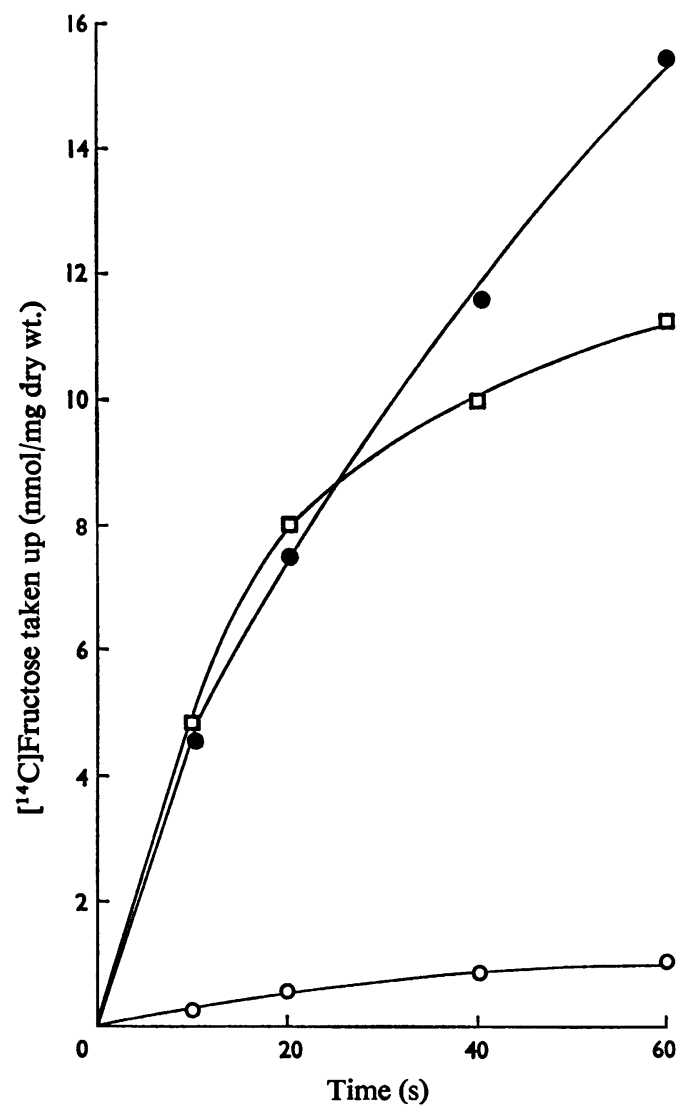

Fig. 4. Uptake of $\left[{ }^{14} \mathrm{Clfructose}\right.$ at $20^{\circ} \mathrm{C}$ by washed suspensions of the mutant $A T 2243-11^{\mathrm{c}}-25$ and of its parent organism $A T$ 2243-11

The uptake of $0.1 \mathrm{~mm}-\left[\mathrm{U}-{ }^{14} \mathrm{C}\right]$ fructose, at $20^{\circ} \mathrm{C}$, by suspensions of the mutant grown in medium containing $25 \mathrm{~mm}$-glycerol ( $\square$ ), and of the parent organism grown in this medium ( 0 ) or in medium containing $20 \mathrm{~mm}$-fructose $(\bullet)$, was measured as described in the Materials and Methods section.

can act as an inducer of the fructose-phosphoenolpyruvate phosphotransferase system; the accumulation of the phosphate ester by mutants blocked in the catabolism of that substance would thus concomitantly de-repress the fructose uptake system. This explanation would require that either fructose or fructose 1-phosphate be produced and accumulate during the metabolism of substances other than fructose or precursors of fructose. No evidence for such a route exists and, indeed, Kelker et al. (1970) failed to detect any accumulation of fructose 1phosphate when glucose was added to suspensions of their A. aerogenes mutant, though large quantities of this phosphorylated sugar accumulated when fructose was also added.

A third possibility is that sugars used as growth substrates are contaminated with traces of fructose. This is rendered unlikely by the findings of Kelker et al. (1970) discussed above and by the ubiquity of the phenomenon in the three organisms studied. It is also relevant to recall that $E$. coli mutants devoid of galactokinase activity, which accumulate galactose 1phosphate, form other enzymes of galactose metabolism constitutively (Wu, 1967); if the third explanation were correct, growth sugars would have to be contaminated also with galactose. These possibilities remain to be tested.

We thank Dr. A. L. Taylor (Denver, Colo., U.S.A.) for the gift of strain AT 2243, the grandparent of the mutant here described, and the Science Research Council for support under Grant B/SR/7246.

\section{References}

Adelberg, E. A., Mandel, M. \& Chen, G. C. C. (1965) Biochem. Biophys. Res. Commun. 18, 788-795

Ashworth, J. M. \& Kornberg, H. L. (1966) Proc. Roy. Soc. Ser. B 165, 179-188

Böck, A. \& Neidhardt, F. C. (1966) J. Bacteriol. 92, 470476

Bray, G. A. (1960) Anal. Biochem. 1, 279-285

Cozzarelli, N. R., Koch, J. P., Hayashi, S. \& Lin, E. C. C. (1965) J. Bacteriol. 90, 1325-1329

Englesberg, E. \& Baron, L. S. (1959) J. Bacteriol. 78, 675-686

Englesberg, E., Anderson, R. L., Weinberg, R., Lee, N., Hoffee, P., Huttenhauer, G. \& Boyer, H. (1962) J. Bacteriol. 84, 137-146

Ferenci, T. \& Kornberg, H. L. (1971a) FEBS Lett. 13, 127-130

Ferenci, T. \& Kornberg, H. L. (1971b) FEBS Lett. 14, 360-363

Ferenci, T., Kornberg, H. L. \& Smith, J. (1971) FEBS Lett. 13, 133-136

Fraenkel, D. G. (1968a) J. Biol. Chem. 243, 6451-6457

Fraenkel, D. G. (1968b) J. Biol. Chem. 243, 6458-6463

Gay, P. \& Rapoport, G. (1970) C. R. Acad. Sci. Ser. D 271, 374-377

Gay, P., Carayon, A. \& Rapoport, G. (1970) C. R. Acad. Sci. Ser. D 271, 263-266

Gorini, L. \& Kaufman, H. (1959) Science 131, 604-605

Hanes, C. S. \& Isherwood, F. A. (1949) Nature (London) $164,1107-1112$

Hanson, T. E. \& Anderson, R. L. (1968) Proc. Nat. Acad. Sci. U.S. 61, 269-276

Kelker, N. E., Hanson, T. E. \& Anderson, R. L. (1970) J. Biol. Chem. 245, 2060-2065

Kornberg, H. L. (1972) in The Molecular Basis of Biological Transport, Miami Winter Symposium (Woessner, J. F. \& Huijing, F., eds.), vol. 3, pp. 157-180, Academic Press, New York and London

Kornberg, H. L. (1973) Proc. Roy. Soc. Ser. B in the press 
Kornberg, H. L. \& Reeves, R. E. (1972) Biochem. J. 128, 1339-1344

Kundig, W. \& Roseman, S. (1971) J. Biol. Chem. 246, 1393-1406

Kundig, W., Ghosh, S. \& Roseman, S. (1964) Proc. Nat. Acad. Sci. U.S. 52, 1067-1074

Kurahashi, K. \& Wahba, A. J. (1958) Biochim. Biophys. Acta 30, 298-302

Lin, E. C. C. (1970) Annu. Rev. Genet. 4, 225-262

Marquet, M., Wagner, M.-C., Delobbe, A., Gay, P. \& Rapoport, G. (1970) C. R. Acad. Sci. Ser. D 271, $449-452$
Morgan, M. J. \& Kornberg, H. L. (1969) FEBS Lett. 3, 53-56

Nikaido, H. (1961) Biochim. Biophys. Acta 48, 460-469

Reeves, R. E., Warren, L. G. \& Hsu, D. S. (1966) J. Biol. Chem. 241, 1257-1261

Sebastian, J. \& Asensio, C. (1967) Biochem. Biophys. Res. Commun. 28, 197-202

Solomon, E. \& Lin, E. C. C. (1972) J. Bacteriol. 111, 566-574

Steinitz, K. (1961) Anal. Biochem. 2, 497-501

Wawszkiewicz, E. J. (1961) Anal. Chem. 33, 252-254

Wu, H. C. P. (1967) J. Mol. Biol. 24, 213-223 